\title{
Morphological classification of bovine ovarian follicles
}

\author{
R J Rodgers and H F Irving-Rodgers \\ The Robinson Institute, Research Centre for Reproductive Health, Discipline of Obstetrics and Gynaecology, \\ University of Adelaide, Adelaide, South Australia 5005, Australia
}

Correspondence should be addressed to $R$ J Rodgers; Email: ray.rodgers@adelaide.edu.au

\begin{abstract}
Follicle classification is an important aid to the understanding of follicular development and atresia. Some bovine primordial follicles have the classical primordial shape, but ellipsoidal shaped follicles with some cuboidal granulosa cells at the poles are far more common. Preantral follicles have one of two basal lamina phenotypes, either a single aligned layer or one with additional layers. In antral follicles $<5 \mathbf{~ m m}$ diameter, half of the healthy follicles have columnar shaped basal granulosa cells and additional layers of basal lamina, which appear as loops in cross section ('loopy'). The remainder have aligned single-layered follicular basal laminas with rounded basal cells, and contain better quality oocytes than the loopy/columnar follicles. In sizes $>5 \mathrm{~mm}$, only aligned/rounded phenotypes are present. Dominant and subordinate follicles can be identified by ultrasound and/or histological examination of pairs of ovaries. Atretic follicles $<5 \mathrm{~mm}$ are either basal atretic or antral atretic, named on the basis of the location in the membrana granulosa where cells die first. Basal atretic follicles have considerable biological differences to antral atretic follicles. In follicles $>5 \mathrm{~mm}$, only antral atresia is observed. The concentrations of follicular fluid steroid hormones can be used to classify atresia and distinguish some of the different types of atresia; however, this method is unlikely to identify follicles early in atresia, and hence misclassify them as healthy. Other biochemical and histological methods can be used, but since cell death is a part of normal homoeostatis, deciding when a follicle has entered atresia remains somewhat subjective.

Reproduction (2010) 139 309-318
\end{abstract}

\section{Introduction}

The adult ovary contains a reserve of inactive primordial follicles. Each contains a small non-growing oocyte and a layer of non-dividing pregranulosa cells encapsulated by the follicular basal lamina. Every day a number of primordial follicles become active, and the oocyte commences growing while the granulosa cells begin to divide. As the granulosa cells divide, the number of layers of cells (called the membrana granulosa or follicular epithelium) around the oocyte increases, and the follicular basal lamina expands. Later in development, a fluid-filled cavity or antrum forms and specialized stromal layers, the theca interna and externa, develop. Only follicles that reach the stage of having a large antrum, and in the follicular wave following regression of corpora lutea, can ovulate an oocyte in response to the surge release of $\mathrm{LH}$. Following ovulation, the granulosa cells and thecal cells differentiate into the large and small luteal cells of the corpus luteum, and the vascular supply of the corpus luteum is derived from the capillaries of the theca interna. All non-ovulating follicles undergo atresia and regression.

Since the development and regression of follicles are associated with major structural and functional changes, it is important to classify follicles accurately as healthy or atretic at all stages of development and to subclassify them further into the different isoforms that exist at most stages. Classification enables us to better compare studies and also assists us to focus on subtleties in follicles that might otherwise have gone unnoticed. Unfortunately, numerous studies have been conducted on follicles or their cells with no effort to ensure these are from similar follicular types and this has lead to misinformation about follicular development. Even though the follicles have been classified into healthy and atretic, a number of different methods have been used to classify atresia, including histology, biochemical markers and ultrasonagraphy; and while there may be no consensus on the best method for classifying atresia, the use of different methods leads to different groupings of follicles from one method to another. Here, we review the approaches to classifying follicles from cattle. Cattle are not only important agricultural species but their ovarian follicle dynamics makes them ideal models for humans (Adams \& Pierson 1995), including the changes that occur on ageing at menopause (Malhi et al. 2005).

\section{Primordial to preantral follicles}

Primordial follicles in most species are identified histologically on the basis of a small non-growing oocyte, without a zona pellucida and surrounded by flattened granulosa cells (Fig. 1; Fair et al. 1997). 

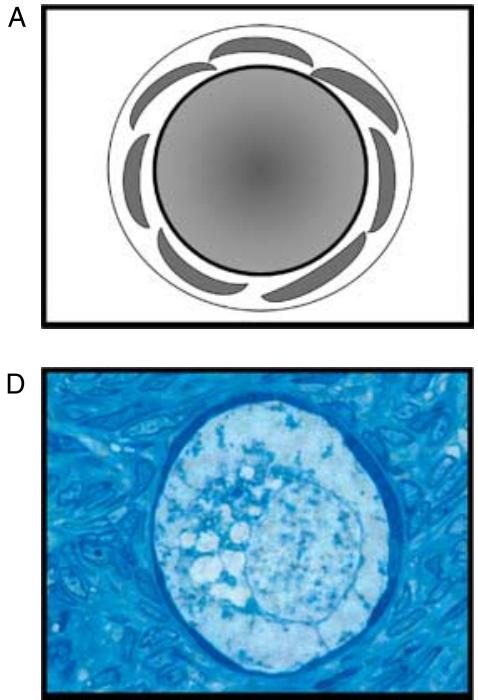

B

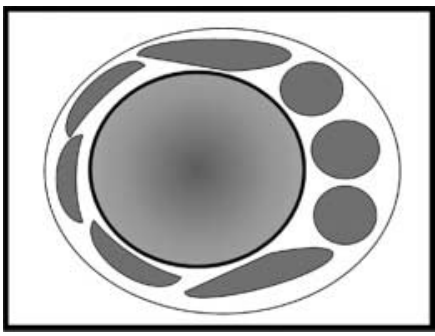

E

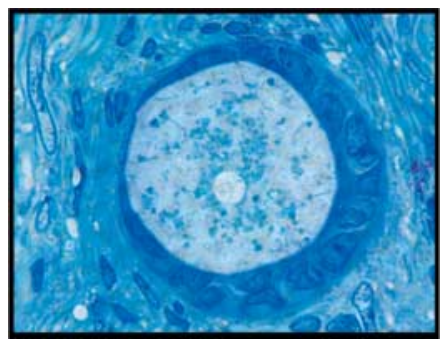

C

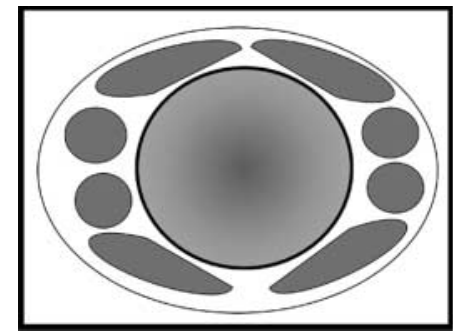

$\mathrm{F}$

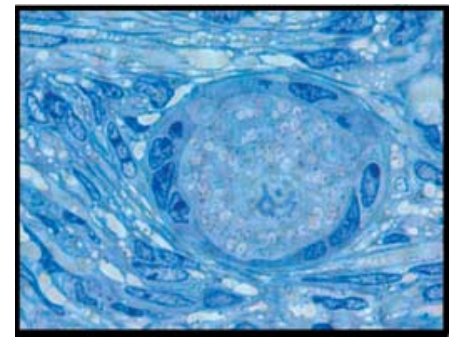

Figure 1 Cartoons and light micrographs (methylene blue-stained section of plastic embedded tissues) of human (D and E) and bovine (F) follicles illustrating the classical primordial follicle shape ( $A$ and $D)$, the human transitional shape (B and $E$ ) and the common ellipsoid shape of bovine follicles (C and F).

The follicles appear this way because the oocyte is not enlarging and the granulosa cells are not replicating. Once activated, the primary follicles have an enlarging oocyte around which the zona pellucida will form, and a layer of granulosa cells that have become cuboidal in shape (Fair et al. 1997). The cells are presumably cuboidal because they have commenced replicating and cells 'round-up' at the prophase and metaphase allowing spindle formation for division to subsequently occur (Boucrot \& Kirchhausen 2008, Rosenblatt 2008). In support of this, it has been observed directly in the mouse ovary that the cuboidal granulosa cells divide more than the flat cells (Da Silva-Buttkus et al. 2008).

In both bovine (van Wezel \& Rodgers 1996) and human ovaries (Gougeon \& Chainy 1987), other morphological variations of primordial and primary follicles are also observed. In bovine ovaries, $83 \%$ of follicles that are less mature than the primary stage are ellipsoid in shape with cuboidal cells located at the poles of the follicle (Fig. 1). These have been interpreted to be primordial follicles with an ellipsoid shape imposed upon them by the surrounding bundles of collagen fibrils (van Wezel \& Rodgers 1996). In the humans, an intermediate form has been observed in which some granulosa cells (usually on one side of the follicle) are cuboidal in shape (Fig. 1; Gougeon \& Chainy 1987). These follicles are as numerous as the true primordial follicles and of the same size, with oocytes of a similar size, but with more granulosa cells seen in cross section (Gougeon \& Chainy 1987). The terms 'transitional' or 'intermediate' are commonly used to describe these follicles (Stubbs et al. 2007, Westergaard et al. 2007, Rice et al. 2008). This is potentially misleading if it is interpreted to mean that these follicles are in a transition stage from primordial to primary. Furthermore, primordial follicles that have been activated but not yet developed to the primary stage would be expected to be few in number, unless the rate of cell division was very slow. This is very unlikely to be the case as evidence from rat studies would indicate (Meredith et al. 2000). Thus, we believe the use of terms intermediate or transitional should not be used to necessarily indicate transition from primordial to primary follicle.

Preantral follicles in bovine (Irving-Rodgers \& Rodgers 2000) and also human (Irving-Rodgers et al. 2008) can be classified into two groups depending on the morphological phenotype of the follicular basal lamina. In both species, some follicles have a conventional basal lamina of a single layer aligned to the surface of the basal granulosa cells, which at the preantral stage in both species are substantially thicker or even partially laminated than either the primordial or the antral follicles. Preantral follicles with additional layers of basal lamina have also been observed. Loops of basal lamina are seen in cross sections and are connected to additional layers closer to the granulosa cell surface (Fig. 2). Cellular projections emanating from the basal surface of the basal granulosa cells and membranebound vesicles often at the end on these processes and adjacent to the basal lamina are also present (Irving-Rodgers \& Rodgers 2000). No studies comparing these two types of follicles at the preantral stage have been conducted in either bovine or human, but there are clear differences at the antral stages as discussed below.

\section{Healthy antral follicles}

During antral follicle growth, there is both replication of granulosa cells and formation and expansion of the follicular antrum containing follicular fluid. The concept 

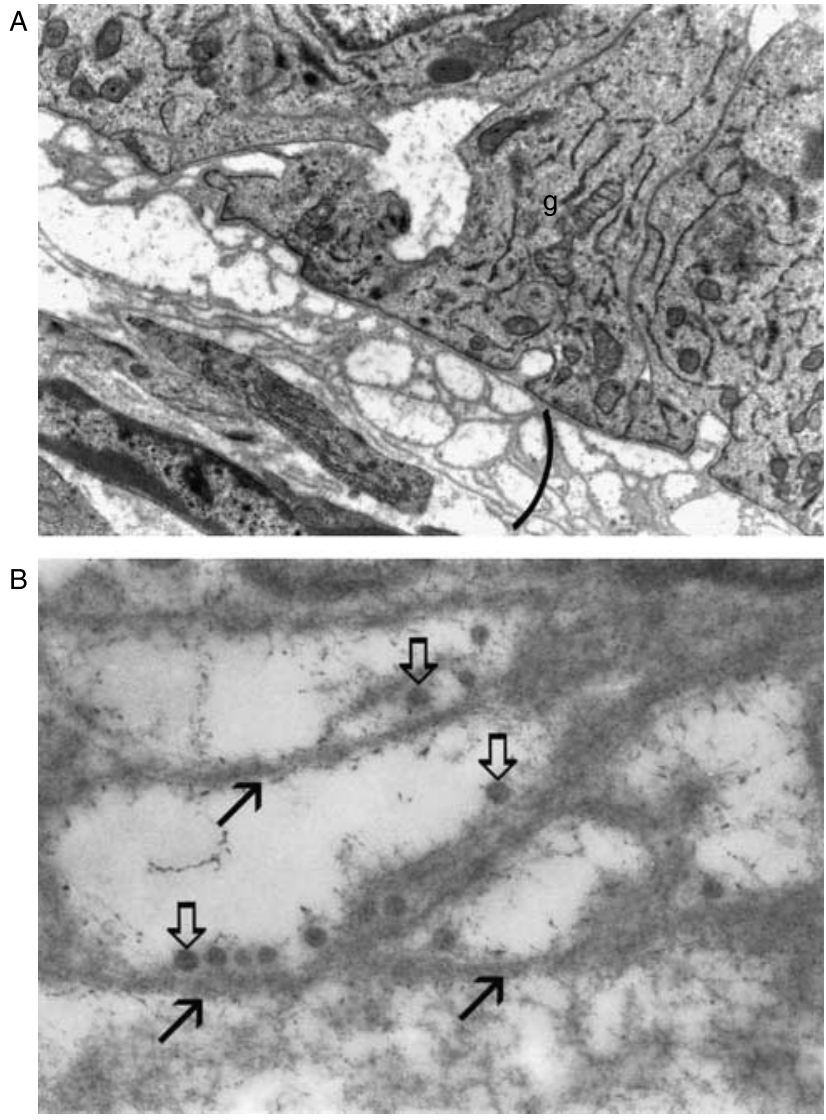

Figure 2 Electron microscopic images of (A) a follicle with a loopy basal lamina (bracket) located at the base of granulosa cells (g) and of (B) a loopy follicular basal lamina with matrix vesicles (arrowheads) located on the granulosa cell side of basal lamina layers (arrows).

that granulosa cell replication and follicular antrum expansion can be regulated differentially (Rodgers et al. 2001) should not be contentious. On the one hand, granulosa cell replication involves regulation of cell cycle and other genes, and can be stimulated by a number of growth factors, and, on the other hand, the formation of follicular fluid is biochemically very different and it has been suggested in bovine to involve the production of osmotically active proteoglycans hyaluronan and versican (Clarke et al. 2006). Evidence of differential regulation also comes from theoretical considerations. It has been argued (Rodgers et al. 1999) that during follicular development there is on average a net 19 doublings in the surface area of the follicle (from a primordial to an $18 \mathrm{~mm}$ bovine follicle, calculated from van Wezel \& Rodgers (1996)), and a net 21 doublings of granulosa cell numbers (if 40 million granulosa cells were present as reported by McNatty et al. (1984) - see van Wezel \& Rodgers (1996)). Thus, it is predicted in bovine that cell layers in the membrana granulosa would increase from one layer, as in primordial follicles, to four (calculated as $(21-19)^{2}=4$ ) layers (Rodgers et al. 1999), and this is close to the number of layers observed in bovine preovulatory follicles (Irving-Rodgers et al. 2001). However, there is considerable variation in the numbers of layers per follicle during follicle growth (van Wezel et al. 1999b), consistent with a reported variation in the number of granulosa cells obtained from follicles of the same size (McNatty et al. 1979). On the basis of these observations, it was suggested that the rate of granulosa cell proliferation and maturation is not tightly or co-ordinately regulated with the rate of antrum expansion (Rodgers et al. 2001).

The concept of differential regulation of granulosa cell replication and follicular fluid accumulation has been used (Rodgers et al. 2001) to explain two follicle phenotypes (Irving-Rodgers \& Rodgers 2000). These phenotypes in bovine can be identified on morphological and functional criteria. One phenotype has the 'loopy' basal lamina and columnar basal granulosa cells (Irving-Rodgers \& Rodgers 2000) and expression of the RNA subunit of telomerase (TERC) in the antrally situated cells (original data in Lavranos et al. (1999) and discussed in Rodgers et al. (2001)). The other phenotype has an aligned single layer of follicular basal lamina and rounded basal cells that express TERC. In bovine antral follicles up to $5 \mathrm{~mm}$ in diameter, both phenotypes occur in equal proportions, while over $5 \mathrm{~mm}$ in diameter only the latter phenotype is observed (Irving-Rodgers \& Rodgers 2000).

It has been suggested that the shape of the basal granulosa cells reflects the dynamics of the follicle as a whole, rather than individual differences between the cells within the membrana granulosa (Rodgers et al. 1999, van Wezel et al. 1999b). It is known that bovine follicles can expand at different rates whether this is calculated from replication rates of cells (Lussier et al. 1987) or monitored directly by ultrasonography (Fortune et al. 1991, Ginther et al. 1996). It was predicted that if the follicular antrum expansion is slow relative to granulosa cell replication, the layers become compacted leading to one or more of the basal layers of cells being columnar (Fig. 3; Rodgers et al. 2001). This concept linking basal granulosa cell shape and follicular basal lamina phenotype with the rate of follicular antrum expansion is also supported by the observation that columnar basal granulosa cells and loopy basal laminas are not observed in follicles approaching or past the size of dominance where the rate of antrum expansion is greater (> $5 \mathrm{~mm}$ (van Wezel et al. 1999a, Irving-Rodgers \& Rodgers 2000)), and in follicles identified as dominant by ultrasonography (Irving-Rodgers et al. 2002).

It has been speculated as illustrated in Fig. 4 that follicles with a loopy follicular basal lamina are slower growing, producing excess basal lamina that is subsequently shed (Rodgers et al. 2001) from the basal surface of the granulosa cells by budding off areas of the surface membrane containing focal adhesions and thus producing the observed membrane-bound vesicles as occurs on release of fibroblasts from collagen matrix 
A

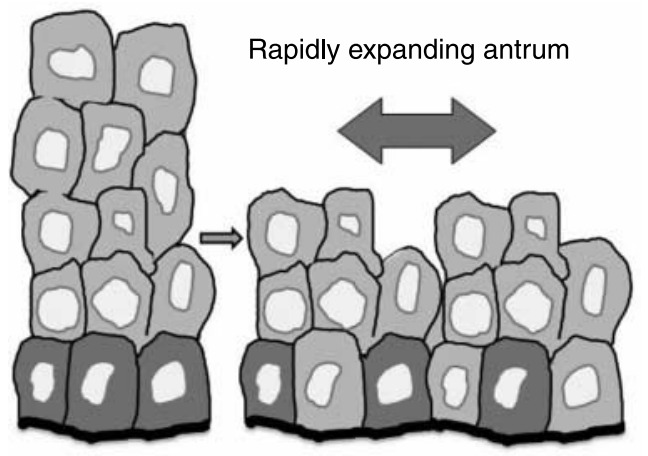

B

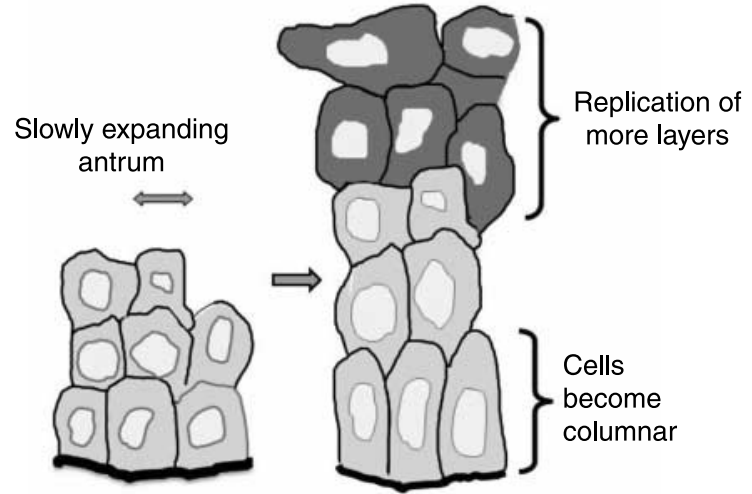

Figure $3 \mathrm{~A}$ cartoon illustrating the effects of differential rates of antrum expansion. (A) A fast rate reduces the numbers of layers and, with ample room to accommodate the cells, they take up their natural relaxed rounded shape. (B) A slow rate of antrum expansion leads to a build-up of layers and, with little room to accommodate cells, the basal cells pack in and become columnar in shape.

(Lee et al. 1993). Upon resynthesis of basal lamina at the basal cell surface, a loop in cross section is produced boarded by the new and the shed basal lamina. The corollary of this is that for follicles of the same size, the one with a loopy basal lamina has been growing for longer. It was on this basis that we sought to compare the quality of the oocytes in the two types of follicles. Follicles with loopy follicular basal lamina were found to have significantly and substantially poorer quality oocytes with only $28 \%$ developing to blastocyst following in vitro maturation, fertilization and culture to blastocyst, compared with $65 \%$ for the follicles with an aligned basal lamina (Irving-Rodgers et al. 2009b). No differences in the concentrations of insulin-like growth factor-binding proteins (IGFBPs; Irving-Rodgers et al. 2003a) or steroid hormones (Irving-Rodgers et al. 2003b) in follicular fluids have been observed between these follicles types. That the oocyte quality is poorer may stem from the possibility that these follicles may be slower growing and hence 'older' in terms of time since activation.

Alternatively, oocytes in follicles with a loopy basal lamina may already be of poor quality. Oocyte-derived growth factors, such as BMP15 and GDF9, are known to affect follicular cells (Hussein et al. 2005, McNatty et al. 2006). It could be that oocytes from follicles with a loopy follicular basal lamina might not adequately stimulate replication of granulosa cells or antrum expansion leading to the observed loopy follicular basal lamina phenotype. If this was the case, then these follicles with a loopy follicular basal lamina could represent an early form of atresia prior to any recognizable evidence of cell death. Since the oocytes of older women are of poorer quality (Broekmans et al. 2009) and since in cows follicle numbers in a wave decline with age (Malhi et al. 2005), it would be interesting to know whether such ovaries contain an increased proportion of follicles with loopy basal lamina.

\section{Dominant and subordinate follicles}

In cows, there are two or three waves of follicular development during an oestrous cycle (Fortune et al. 1991, Ginther et al. 1996). Each wave consists of the contemporaneous appearance, observable by ultrasonography, of three to six follicles $>5 \mathrm{~mm}$ in diameter
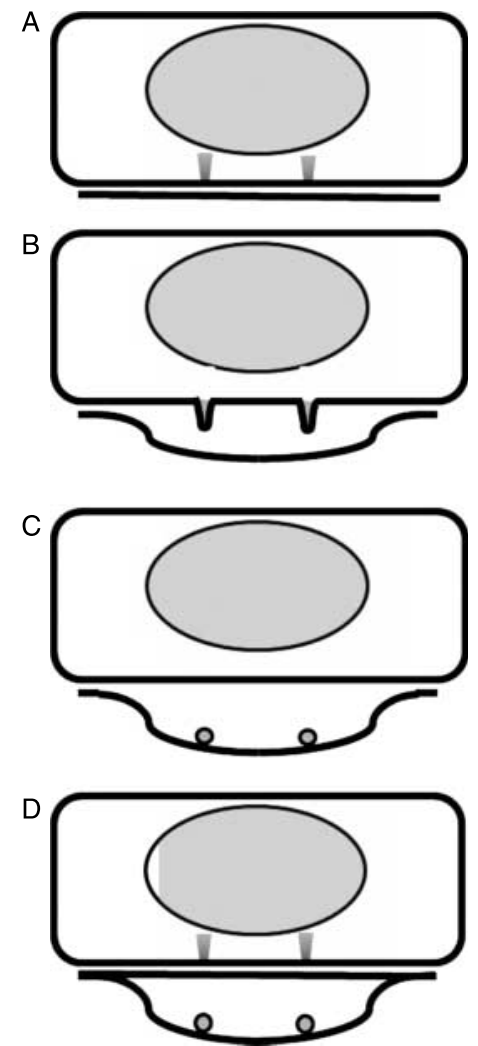

Figure 4 Cartoon illustrating sequentially (A-D) how the loopy follicular basal lamina phenotype could develop. (A) Aligned single layer of basal lamina with focal adhesions on cell surface. (B) Blebing of cell surface at location of focal adhesion. (C) Release and formation of matrix vesicles from the cell surface of the area occupied by focal adhesions. (D) Synthesis of a new basal lamina at the granulosa cell surface with the original basal lamina with attached matrix vesicles located further away from the cell surface. 
(ovulatory size is $12-20 \mathrm{~mm}$ ) and, several days after the emergence of a wave, one follicle becomes larger than the rest at a time called deviation which occurs when the follicle is about $8 \mathrm{~mm}$ in diameter (Fortune et al. 1991, Ginther et al. 1996). The larger, dominant follicle continues to grow at a faster rate (Ginther et al. 2001), while the smaller follicles in the cohort, referred to as subordinate follicles, will eventually regress (Fortune et al. 1991, Ginther et al. 1996). The corollary of these dynamic changes in follicle growth is that healthy antral follicles are clearly of two types, dominant and subordinate, characterized by whether they are actively growing or growing slowly respectively.

It has been shown in cows that as follicles grow from sizes smaller to larger than deviation, the expression in granulosa cells of FSH receptor declines, while $\mathrm{LH}$ receptor, CYP11A1 (cholesterol side-chain cleavage), $3 \beta$-hydroxysteroid dehydrogenase (HSD3B) and CYP19A1 (aromatase) increase as do the concentrations of oestradiol $\left(E_{2}\right)$ and progesterone in the follicular fluids (reviewed in Bao \& Garverick (1998), Webb et al. (1999), Fortune et al. (2001), Knight \& Glister (2003) and Beg \& Ginther (2006)). In comparison with subordinate follicles, dominant follicles have elevated follicular fluid $\mathrm{E}_{2}$ concentrations (Fortune et al. 2001, Ouellette et al. 2005, Ryan et al. 2007, Sisco \& Pfeffer 2007) and synthetic capacity (Fortune et al. 2001, Rhodes et al. 2001), and increased free insulin-like growth factor 1 and decreased IGFBP4 and -5 (Beg \& Ginther 2006). The dominant follicle in a first wave of the cycle is also slightly larger than one in a second wave (Manikkam et al. 2001), and these have higher follicular fluid $E_{2}$ concentrations (Wolfenson et al. 1999). No difference in plasma $E_{2}$ concentration was found between cows with two or three follicular waves (Parker et al. 2003), while the ovulatory follicle is larger in cows with two versus three follicular waves (Townson et al. 2002, Parker et al. 2003); however this is not due to differences in growth rates (Townson et al. 2002). A significant negative relationship between transforming growth factor $\beta 1$ (TGFB1) in follicular fluid and follicle diameter occurs at $6.5 \mathrm{~mm}$ (before selection), but not at later stages (Ouellette et al. 2005). In addition, TGFB1 inhibits FSHstimulated $E_{2}$ secretion from granulosa cells of small antral follicles (Ouellette et al. 2005, Zheng et al. 2008) as well as CYP19A1 expression, but not CYP11A1 (Zheng et al. 2008).

The use of ultrasonography of cows, carried out at least daily, is highly recommended for identifying dominant and subordinate follicles for in vivo measurements. However, there are some caveats with this approach. The subordinate follicles undergo atresia some time post deviation when expansion ceases. However, there is clearly a window before this change in growth is observed by ultrasonography when the follicle is atretic by histological or biochemical observation and from our own observations when a follicle has been observed to have ceased growth on daily ultrasounds; histologically, the follicle can be well advanced into atresia with substantial death of granulosa cells (Irving-Rodgers et al. 2001). Furthermore, many studies are conducted on follicles in an artificially induced first wave of a cycle. While this makes the conduct of the experiments easier, these follicles may not be identical to normal cyclic follicles. A more physiological approach is to synchronize the cycle, monitor oestrous expression and examine the follicles in the first wave of the subsequent cycle (Ireland et al. 2008). In this case, the animals are still relatively well synchronized, but the follicles are not artificially induced.

Ovaries from non-stimulated cows collected at an abattoir can also be informative (Irving-Rodgers et al. 2009a) especially if additional information is available on the ages, breed and husbandry. If pairs of ovaries from each animal are collected separately and the three largest follicles identified and a sample of the follicle wall examined histologically, it is possible to identify dominant follicles (largest) that can be subdivided further into partially dominant if the subordinate follicles are healthy, or fully dominant if the subordinate follicles are atretic. This subdivision of dominant follicles clearly identifies follicles earlier and later post deviation respectively. Furthermore, the subordinate follicles can be classified as healthy or atretic by this approach. When using non-pregnant animals, the age of the corpora lutea in these pairs of ovaries can be assessed by gross (Ireland et al. 1980) or histological (Rodgers et al. 1986, Fields \& Fields 1996) examination. This can be used to assign follicles into either the first or subsequent (second or third) waves of the cycle. Importantly, the sizes of follicles collected this way will differ from those recorded from ultrasound and estimates suggest they can be up to $3 \mathrm{~mm}$ greater (Sirois \& Fortune 1988). The latter method measures diameters from the granulosa-follicular fluid interface and the former measures the dissected size of the follicle, which includes the theca interna and part of the externa at least (unpublished histological observations), and these differences should be considered when comparing data obtained by these different methods.

\section{Cell death in follicles}

Atresia of follicles leads to loss of the whole follicle and not just death of single cells, even if death of one cell, such as the oocyte, is observed early in the process. Additionally, even though the focus is often on cell death, atresia is also an active cellular process with resorption of the follicle involving macrophage infiltration, phagocytosis, migration of fibroblasts from the theca and production of collagen, which are some of the processes observed in wound healing (Martin 1997, Schultz \& Wysocki 2009). Which cell(s) die first and 
perhaps initiate atresia varies during follicular development. During follicle growth, different cell(s) may vary in their susceptibility to death and if these cells are irreplaceable then this would result in follicular atresia. At the bovine preantral stage, oocytes are reported to be the first to die (Rajakoski 1960), in contrast to the antral stage where granulosa cells die first, and in one form of atresia (discussed below) thecal cells, including steroidogenic and endothelial cells (Clark et al. 2004), also die very early in atresia. When atresia is initiated by a large amount of cell death, this could be due to loss of growth factor support such as TGF $\alpha$ (Wang et al. 2002), or that expression of Fas or Fas ligand (Porter et al. 2000, Quirk et al. 2004) could be involved in initiating the process. But where one cell, such as the ooctye, is involved in the initiation of atresia, this is likely to include a failure in development of the oocyte, whereas failure of a few granulosa cells would not have the same consequences. In fact, cell death is a normal part of tissue homoeostatis. Therefore, a limited amount of cell death of granulosa or thecal cells would not be unexpected in a healthy follicle (Jolly et al. 1994), contributing to the difficulty of defining precisely when a follicle has commenced atresia, and estimation of the required level of cell death to indicate atresia is imprecise.

Modes of cell death include apoptosis, autophagy, cornification and necrosis; and all forms have been observed in granulosa cells (Jolly et al. 1994, van Wezel et al. 1999a, D'Haeseleer et al. 2006); however, their occurrence does not necessarily indicate atresia. Hence, the term apoptosis should not be used when the term atresia is meant. A consensus statement on the nomenclature of cell death (Kroemer et al. 2009) also recommends that the methods by which cell death has been observed should always be reported when reporting the degree of cell death, e.g. apoptosis as observed by DNA fragmentation or karyorrhexis. Examples of why this is important in follicles include the observation in bovine follicles of morphological dead pyknotic nuclei that can be TUNEL negative (Braw-Tal \& Roth 2005) or not have DNA ladders by COMET (van Wezel et al. 1999a). Using the latter two methods would not have identified all the dead cells.

Historically, atresia was first classified by gross and morphological criteria. These criteria assessed follicles that were then used to identify biochemical changes, such as steroid hormones in follicular fluid. Concentrations of steroid hormones in follicular fluids have since been used as surrogate markers of atresia; however, this approach should be applied with caution as clearly the levels of hormones change with both growth and development, as well as with atresia. Later, direct physiological observation of follicle size using ultrasound was able to identify follicles decreasing in size, and hence in advanced stages of atresia. Recently, with the interest in the mechanisms of cell death, a number of additional biochemical methods often in combination with histology or FACS analysis have been used. Since characteristics of atresia differ with different sizes of follicles, atresia at different sizes of antral follicles is considered separately below.

\section{Atresia of antral follicles $<5 \mathrm{~mm}$ in diameter}

Many studies of atresia in the bovine ovary have been confounded because there is more than one type of atresia, and a seminal report on follicular atresia (Rajakoski 1960) misdescribed one form by misidentifying granulosa cells as theca cells in what is now called 'basal atresia'. Marion et al. (1968) accurately described this major type of atresia misidentified by Rajakoski, but described incorrectly how this form of atresia originated. On re-examination of these forms, they were renamed as 'antral (apical may have been a better

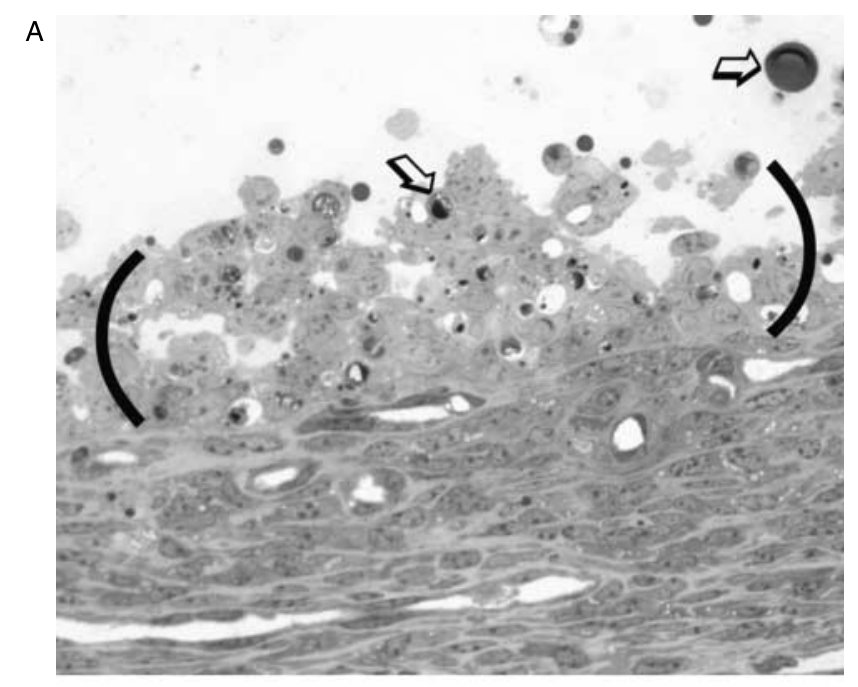

B

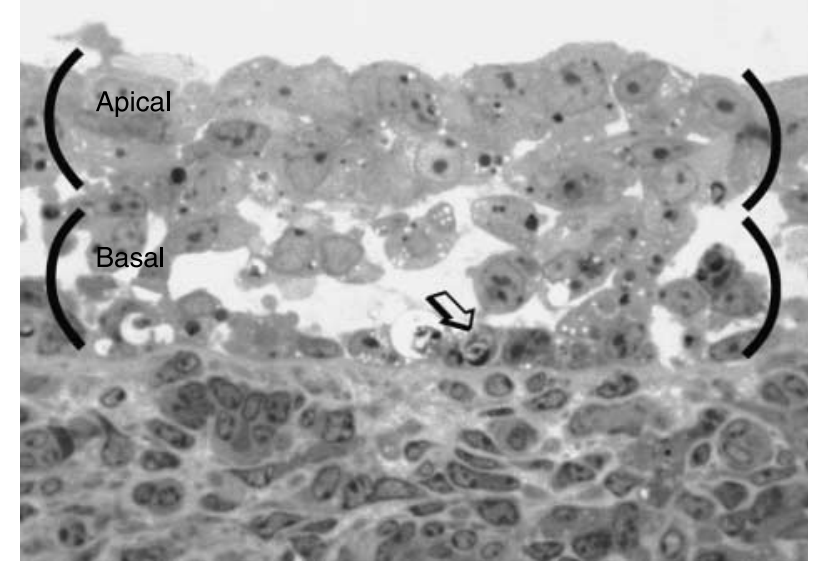

Figure 5 Light micrographs of bovine antral (A) and basal (B) atretic follicles showing the location of granulosa cells (brackets) and examples of dying cells (arrowheads), which in the basal atretic follicles are in the basal areas of the membrana granulosa, while the apical area shows granulosa cells of increased size. 
term) atresia' and basal atresia, based upon which granulosa cells die first (Irving-Rodgers et al. 2001). Antral atresia is characterized by early destruction of the layers of the membrana granulosa closest to the antrum, while the most basal cells remained intact until later (Fig. 5). Numerous pyknotic nuclei are first observed in the most antral or apical layers and in the antrum close to the membrana granulosa. This is the classic description of atretic follicles and is observed in many species and occurs at all sizes of follicle development in the bovine and almost universally in large follicles $(>5 \mathrm{~mm}$ in diameter), including non-ovulating dominant follicles. Basal atretic follicles are as prevalent as the antral atretic follicles in sizes up to $5 \mathrm{~mm}$ in diameter (Irving-Rodgers et al. 2001) and are characterized by initial destruction of the most basal layer of granulosa cells, whereas the cells in the most antral layers remain associated with each other and are predominantly healthy until later in atresia (Fig. 5).

The phenotype of the basal atretic follicles observed in bovine is substantially different to the antral atretic follicles (illustrated in Fig. 6). The follicular basal lamina of basal atretic follicles is often breached by macrophages, which then phagocytose dying basal granulosa cells (Irving-Rodgers et al. 2001). Importantly, in these basal atretic follicles, the surviving antral granulosa cells, now detached from the basal lamina, express CYP11A1 and HSD3B (healthy and antral atretic follicles

A

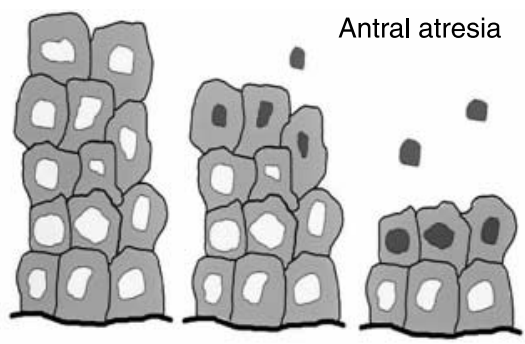

B

Basal atresia

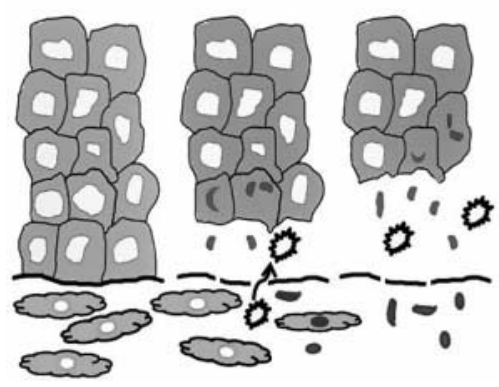

$\uparrow$ Progesterone $\downarrow$ Androstenedione $\downarrow$ Testosterone

$\uparrow$ CYP11A1 $\uparrow$ HSD3B

Macrophage infiltration $\downarrow$ INSL3, death of steroidogenic and endothelial cells

Figure 6 A cartoon of antral (A) and basal (B) atresia illustrating the changes over three time points as cell death progresses either from the apical regions or from the basal region. In basal atresia, the known changes in follicular fluid hormone, expression of steroidogenic enzymes in the apical cells, breaching of the follicular basal lamina and migration of cells from the theca including macrophages, and death of steroidogenic cells and endothelial cells in the theca and changes in insulin-like factor 3 in the thecal interna are indicated. of the same size do not), and these follicles have substantially elevated progesterone levels in follicular fluid (Irving-Rodgers et al. 2003 b). In basal atretic follicles, there is also an increased deposition of collagen within the theca, and early death of endothelial and steroidogenic thecal cells as observed by TUNEL labelling and morphology (Clark et al. 2004) and reduced expression of insulin-like factor 3 in the theca (Irving-Rodgers et al. 2003a). The early decline of the theca in these follicles is also consistent with reduced levels of thecal-derived androstenedione and testosterone in the follicular fluid compared with healthy and antral atretic follicles of the same size (Irving-Rodgers et al. 2003 b). It has been suggested that the basal atretic follicles develop from antral atretic follicles later in the process of atresia (Braw-Tal \& Roth 2005); however, in the absence of an intermediate phenotype between antral and basal atresia as would be expected if one morphed into the other, together with the restriction of basal atresia to sizes $<5 \mathrm{~mm}$, and with two distinct phenotypes of healthy follicles that correspond to the same size ranges as for the two atretic phenotypes, it is more likely that these atretic follicle phenotypes are separate identities.

Considering bovine follicles $<5 \mathrm{~mm}$ only, the elevated levels of progesterone in follicular fluid indicate basal atresia (Irving-Rodgers et al. 2003b) and this was also observed in an earlier study of bovine follicles $>5 \mathrm{~mm}$ diameter, which were classified histologically as either healthy or atretic (Grimes et al. 1987). In that study, $\sim 6 \%$ of the follicles were classified as 'atreticluteinized' and described as having elongated and hypertrophied granulosa cells and a disorganized theca. These follicles had progesterone levels four to eightfold greater in the follicular fluid in comparison with healthy follicles or those classified as atretic by standard criteria (antral atresia description). Additionally, these atretic-luteinized follicles had a low ratio of progesterone to $E_{2}$. The atretic-luteinized follicles were probably basal atretic follicles as their description is very similar to the description of basal atretic follicles (Irving-Rodgers et al. 2003b).

Bovine antral atretic follicles $<5 \mathrm{~mm}$ were observed to have no appreciable difference in the levels of progesterone, androstenedione or testosterone to those of healthy follicles of the same size (Irving-Rodgers et al. 2003 b), and this was in agreement with an earlier study using follicles classified as atretic using features observed on fresh tissues under $10 \times$ magnification (McNatty et al. 1984). These studies also found either a lower level of $\mathrm{E}_{2}$ (Irving-Rodgers et al. 2003b) or no significant reduction (McNatty et al. 1984) respectively at these sizes of follicles. In a latter study, however, significant differences in $E_{2}$ production by cultured granulosa cells from follicles classified as healthy and atretic were observed (Henderson et al. 1987), indicating that there is a difference in granulosa cells in 
their capacity to produce $\mathrm{E}_{2}$, at least in vitro, at these follicles sizes. However, differences between follicles in $E_{2}$ synthetic capacity might not be sufficient to reliably use this method as an indicator of atresia.

What measurements are best to identify atresia in small antral bovine follicles? Histological observations are far less contentious, but a word of warning. When processing a biopsy of a follicle for histology, it is possible to lose a proportion of the granulosa cells during tissue harvesting, which does not occur if the whole follicle is processed without rupture. This is especially true for basal atretic follicles, and it is recommended to only classify follicles when granulosa cells are observed.

\section{Atresia of antral follicles $>5 \mathrm{~mm}$ in diameter}

In larger bovine follicles, no basal atresia is evident (Irving-Rodgers et al. 2001), making classification simpler. That is not to say there are no different types of atresia in these large follicles, and it has been observed that the level of Fas expression in thecal cells was greater in the subordinate follicles undergoing atresia than in dominant follicles undergoing atresia (Porter et al. 2001). While this study was not extensive in terms of time points or numbers, it does indicate that some complexity of the atresia processes also occurs in larger follicles.

Numerous studies of bovine follicles have measured steroid hormone concentrations in follicular fluids with different indicators of atresia or cell death used to determine whether the steroid concentrations are indeed good measures of atresia (Ireland \& Roche 1983, McNatty et al. 1984, Grimes et al. 1987, Jolly et al. 1994). The consensus is that healthy follicles have higher levels of $E_{2}$ than atretic follicles, and atretic follicles have higher levels of progesterone or thecal products such as testosterone or androstenedione for the same size of follicle. The terms 'oestrogen active' or 'inactive' are used to describe healthy or atretic follicles respectively. However, the absolute levels of progesterone, androstenedione and $E_{2}$ also increase with increasing follicle size up until ovulation (Ireland \& Roche 1983), and hence absolute levels can only be used as a basis of comparison between similar sized follicles. To overcome this problem, ratios of $E_{2}$ to progesterone or testosterone were used and shown to decrease substantially on atresia. However, Grimes et al. (1987) found no appreciable differences in the concentration of progesterone, testosterone or $\mathrm{E}_{2}$ in 'intermediate atretic' follicles that, while not as advanced as the 'strongly atretic' follicles, had histologically obviously become atretic. The strongly atretic follicles did have a twofold reduction in $E_{2}$ and a twofold elevation in levels of progesterone, but if relying on these measurements alone or ratios thereof, many atretic follicles would be misclassified as healthy. It is thus suspected that as follicles enter atresia, which can be observed histologically, changes in steroid hormone concentrations occur as a later event. This is not unexpected as death of cells is sequential, starting at the antrum and progressing to the basal lamina over time. This produces a window in which both live and dead cells are present, and presumably the live ones continue their steroid secretory function until dead.

Thus, it is recommended that, if it is needed, a histological approach be undertaken, either by examination of cell morphology, or in combination with markers of cell death, or direct measurement of apoptosis by such methods of DNA end labelling (Jolly et al. 1994) or FACS sorting of nuclei (Blondin et al. 1996, Lavranos et al. 1999, Hendriksen et al. 2003).

\section{Conclusions}

Since bovine follicles vary greatly in their characteristics during growth and development and atresia, it is necessary to develop criteria for classifying them. A number of different methods have been used to classify follicles and each has its strengths and weaknesses as discussed. Healthy follicles are the easiest to classify and, at nearly all stages of growth, two types of follicles can be identified; primordial follicles of two different shapes but with no known differences between them, preantral follicles of two different follicular basal lamina phenotypes, antral follicles of two different phenotypes based on follicular basal lamina and granulosa cell shape and having oocytes of different qualities but similar levels of follicular fluid steroids and IGFBPs, and then larger follicles that are either dominant or subordinate with differential growth rates and sizes. Atretic follicles $<5 \mathrm{~mm}$ are of two types and these are also easily identified histologically and biochemically for basal atresia. In larger follicles, atresia can be recognized by a number of methods especially when in advanced stages. However, some methods are better than others at identifying early atresia and these should be used to avoid early atretic follicles being misclassified as healthy.

\section{Declaration of interest}

The authors declare that there is no conflict of interest that could be perceived as prejudicing the impartiality of the research reported.

\section{Funding}

The authors are funded by the National Health and Medical Research Council of Australia.

\section{Acknowledgements}

We thank Dr Jim J Ireland of Michigan State University for his constructive comments in the preparation of this manuscript. 


\section{References}

Adams GP \& Pierson RA 1995 Bovine model for study of ovarian follicular dynamics in humans. Theriogenology 43 113-120.

Bao B \& Garverick HA 1998 Expression of steroidogenic enzyme and gonadotropin receptor genes in bovine follicles during ovarian follicular waves: a review. Journal of Animal Science 76 1903-1921.

Beg MA \& Ginther OJ 2006 Follicle selection in cattle and horses: role of intrafollicular factors. Reproduction 132 365-377.

Blondin P, Dufour M \& Sirard MA 1996 Analysis of atresia in bovine follicles using different methods: flow cytometry, enzyme-linked immunosorbent assay, and classic histology. Biology of Reproduction 54 631-637.

Boucrot E \& Kirchhausen T 2008 Mammalian cells change volume during mitosis. PLoS ONE 3 e1477.

Braw-Tal R \& Roth Z 2005 Gene expression for LH receptor, 17 $\alpha$ hydroxylase and StAR in the theca interna of preantral and early antral follicles in the bovine ovary. Reproduction 129 453-461.

Broekmans FJ, Soules MR \& Fauser BC 2009 Ovarian ageing: mechanisms and clinical consequences. Endocrine Reviews 30 465-493.

Clark LJ, Irving-Rodgers HF, Dharmarajan AM \& Rodgers RJ 2004 Theca interna: the other side of bovine follicular atresia. Biology of Reproduction 71 1071-1078.

Clarke HG, Hope SA, Byers S \& Rodgers RJ 2006 Formation of ovarian follicular fluid may be due to the osmotic potential of large glycosaminoglycans and proteoglycans. Reproduction 132 119-131.

Da Silva-Buttkus P, Jayasooriya GS, Mora JM, Mobberley M, Ryder TA, Baithun M, Stark J, Franks S \& Hardy K 2008 Effect of cell shape and packing density on granulosa cell proliferation and formation of multiple layers during early follicle development in the ovary. Journal of Cell Science 121 3890-3900.

D'Haeseleer M, Cocquyt G, Van Cruchten S, Simoens P \& Van den Broeck W 2006 Cell-specific localisation of apoptosis in the bovine ovary at different stages of the oestrous cycle. Theriogenology 65 757-772.

Fair T, Hulshof SC, Hyttel P, Greve T \& Boland M 1997 Oocyte ultrastructure in bovine primordial to early tertiary follicles. Anatomy and Embryology 195 327-336.

Fields MJ \& Fields PA 1996 Morphological characteristics of the bovine corpus luteum during the estrous cycle and pregnancy. Theriogenology 45 1295-1325.

Fortune JE, Sirois J, Turzillo AM \& Lavoir M 1991 Follicle selection in domestic ruminants. Journal of Reproduction and Fertility 43 187-198.

Fortune JE, Rivera GM, Evans AC \& Turzillo AM 2001 Differentiation of dominant versus subordinate follicles in cattle. Biology of Reproduction 65 648-654.

Ginther OJ, Wiltbank MC, Fricke PM, Gibbons JR \& Kot K 1996 Selection of the dominant follicle in cattle. Biology of Reproduction $\mathbf{5 5}$ 1187-1194.

Ginther OJ, Bergfelt DR, Beg MA \& Kot K 2001 Follicle selection in cattle: relationships among growth rate, diameter ranking, and capacity for dominance. Biology of Reproduction 65 345-350.

Gougeon A \& Chainy GB 1987 Morphometric studies of small follicles in ovaries of women at different ages. Journal of Reproduction and Fertility 81 433-442.

Grimes RW, Matton P \& Ireland JJ 1987 A comparison of histological and non-histological indices of atresia and follicular function. Biology of Reproduction 37 82-88.

Henderson KM, McNatty KP, Smith P, Gibb M, $\mathbf{O}^{\prime}$ Keeffe LE, Lun S, Heath DA \& Prisk MD 1987 Influence of follicular health on the steroidogenic and morphological characteristics of bovine granulosa cells in vitro. Journal of Reproduction and Fertility 79 185-193.

Hendriksen PJ, Gadella BM, Vos PL, Mullaart E, Kruip TA \& Dieleman SJ 2003 Follicular dynamics around the recruitment of the first follicular wave in the cow. Biology of Reproduction $692036-2044$.

Hussein TS, Froiland DA, Amato F, Thompson JG \& Gilchrist RB 2005 Oocytes prevent cumulus cell apoptosis by maintaining a morphogenic paracrine gradient of bone morphogenetic proteins. Journal of Cell Science $1185257-5268$.

Ireland JJ \& Roche JF 1983 Growth and differentiation of large antral follicles after spontaneous luteolysis in heifers: changes in concentration of hormones in follicular fluid and specific binding of gonadotropins to follicles. Journal of Animal Science 57 157-167.
Ireland JJ, Murphee RL \& Coulson PB 1980 Accuracy of predicting stages of bovine estrous cycle by gross appearance of the corpus luteum. Journal of Dairy Science 63 155-160.

Ireland JL, Scheetz D, Jimenez-Krassel F, Themmen AP, Ward F, Lonergan P, Smith GW, Perez GI, Evans AC \& Ireland JJ 2008 Antral follicle count reliably predicts number of morphologically healthy oocytes and follicles in ovaries of young adult cattle. Biology of Reproduction 79 1219-1225.

Irving-Rodgers HF \& Rodgers RJ 2000 Ultrastructure of the basal lamina of bovine ovarian follicles and its relationship to the membrana granulosa. Journal of Reproduction and Fertility 118 221-228.

Irving-Rodgers HF, van Wezel IL, Mussard ML, Kinder JE \& Rodgers RJ 2001 Atresia revisited: two basic patterns of atresia of bovine antral follicles. Reproduction 122 761-775.

Irving-Rodgers HF, Mussard ML, Kinder JE \& Rodgers RJ 2002 Composition and morphology of the follicular basal lamina during atresia of bovine antral follicles. Reproduction 123 97-106.

Irving-Rodgers HF, Catanzariti KD, Master M, Grant PA, Owens PC \& Rodgers RJ 2003 a Insulin-like growth factor binding proteins in follicular fluid from morphologically distinct healthy and atretic bovine antral follicles. Reproduction, Fertility, and Development 15 241-248.

Irving-Rodgers HF, Krupa M \& Rodgers RJ 2003b Cholesterol side-chain cleavage cytochrome P450 and 3 $\beta$-hydroxysteroid dehydrogenase expression and the concentrations of steroid hormones in the follicular fluids of different phenotypes of healthy and atretic bovine ovarian follicles. Biology of Reproduction 69 2022-2028.

Irving-Rodgers HF, Morris S, Collett RA, Peura TT, Davy M, Thompson JG, Mason HD \& Rodgers RJ 2008 Phenotypes of the ovarian follicular basal lamina predict developmental competence of oocytes. Human Reproduction 24 936-944.

Irving-Rodgers HF, Harland ML, Sullivan TR \& Rodgers RJ 2009a Studies of granulosa cell maturation in dominant and subordinate bovine follicles: novel extracellular matrix focimatrix is co-ordinately regulated with cholesterol side-chain cleavage CYP11A1. Reproduction 137 825-834.

Irving-Rodgers HF, Morris S, Collett RA, Peura TT, Peura M, Davy M, Thompson JG, Mason HD \& Rodgers RJ $2009 b$ Phenotypes of the ovarian follicular basal lamina predict developmental competence of oocytes. Human Reproduction 24 936-944.

Jolly PD, Tisdall DJ, Heath DA, Lun S \& McNatty KP 1994 Apoptosis in bovine granulosa cells in relation to steroid synthesis, cyclic adenosine $3^{\prime}, 5^{\prime}$-monophosphate response to follicle-stimulating hormone and luteinizing hormone, and follicular atresia. Biology of Reproduction $\mathbf{5 1}$ 934-944.

Knight PG \& Glister C 2003 Local roles of TGF- $\beta$ superfamily members in the control of ovarian follicle development. Animal Reproduction Science 78 165-183.

Kroemer G, Galluzzi L, Vandenabeele P, Abrams J, Alnemri ES, Baehrecke EH, Blagosklonny MV, El-Deiry WS, Golstein P, Green DR et al. 2009 Classification of cell death: recommendations of the nomenclature committee on cell death. Cell Death and Differentiation 16 3-11.

Lavranos TC, Mathis JM, Latham SE, Kalionis B, Shay JW \& Rodgers RJ 1999 Evidence for ovarian granulosa stem cells: telomerase activity and localization of the telomerase ribonucleic acid component in bovine ovarian follicles. Biology of Reproduction 61 358-366.

Lee TL, Lin YC, Mochitate K \& Grinnell F 1993 Stress-relaxation of fibroblasts in collagen matrices triggers ectocytosis of plasma membrane vesicles containing actin, annexins $\mathrm{II}$ and $\mathrm{VI}$, and beta 1 integrin receptors. Journal of Cell Science 105 167-177.

Lussier JG, Matton P \& Dufour JJ 1987 Growth rates of follicles in the ovary of the cow. Journal of Reproduction and Fertility 81 301-307.

Malhi PS, Adams GP \& Singh J 2005 Bovine model for the study of reproductive aging in women: follicular, luteal, and endocrine characteristics. Biology of Reproduction 73 45-53.

Manikkam M, Calder MD, Salfen BE, Youngquist RS, Keisler DH \& Garverick HA 2001 Concentrations of steroids and expression of messenger RNA for steroidogenic enzymes and gonadotropin receptors in bovine ovarian follicles of first and second waves and changes in second wave follicles after pulsatile LH infusion. Animal Reproduction Science 67 189-203.

Marion GB, Gier HT \& Choudary JB 1968 Micromorphology of the bovine ovarian follicular system. Journal of Animal Science 27 451-465. 
Martin P 1997 Wound healing - aiming for perfect skin regeneration. Science 276 75-81.

McNatty KP, Smith DM, Makris A, Osathanondh R \& Ryan KJ 1979 The microenvironment of the human antral follicle: interrelationships among the steroid levels in antral fluid, the population of granulosa cells, and the status of the oocyte in vivo and in vitro. Journal of Clinical Endocrinology and Metabolism 49 851-860.

McNatty KP, Heath DA, Henderson KM, Lun S, Hurst PR, Ellis LM, Montgomery GW, Morrison L \& Thurley DC 1984 Some aspects of thecal and granulosa cell function during follicular development in the bovine ovary. Journal of Reproduction and Fertility 72 39-53.

McNatty KP, Lawrence S, Groome NP, Meerasahib MF, Hudson NL, Whiting L, Heath DA \& Juengel JL 2006 Meat and livestock association plenary lecture 2005. Oocyte signalling molecules and their effects on reproduction in ruminants. Reproduction, Fertility, and Development 18 403-412.

Meredith S, Dudenhoeffer G \& Jackson K 2000 Classification of small type $B / C$ follicles as primordial follicles in mature rats. Journal of Reproduction and Fertility 119 43-48.

Ouellette Y, Price CA \& Carriere PD 2005 Follicular fluid concentration of transforming growth factor- $\beta 1$ is negatively correlated with estradiol and follicle size at the early stage of development of the first-wave cohort of bovine ovarian follicles. Domestic Animal Endocrinology 29 623-633.

Parker KI, Robertson DM, Groome NP \& Macmillan KL 2003 Plasma concentrations of inhibin a and follicle-stimulating hormone differ between cows with two or three waves of ovarian follicular development in a single estrous cycle. Biology of Reproduction 68 822-828.

Porter DA, Vickers SL, Cowan RG, Huber SC \& Quirk SM 2000 Expression and function of Fas antigen vary in bovine granulosa and theca cells during ovarian follicular development and atresia. Biology of Reproduction 62 62-66.

Porter DA, Harman RM, Cowan RG \& Quirk SM 2001 Susceptibility of ovarian granulosa cells to apoptosis differs in cells isolated before or after the preovulatory LH surge. Molecular and Cellular Endocrinology 176 13-20.

Quirk SM, Cowan RG, Harman RM, Hu CL \& Porter DA 2004 Ovarian follicular growth and atresia: the relationship between cell proliferation and survival. Journal of Animal Science $\mathbf{8 2}$ E40-E52.

Rajakoski E 1960 The ovarian follicular system in sexually mature heifers with special reference to seasonal, cyclical, end left-right variations. Acta Endocrinologica 34 1-68.

Rhodes FM, Peterson AJ \& Jolly PD 2001 Gonadotrophin responsiveness, aromatase activity and insulin-like growth factor binding protein content of bovine ovarian follicles during the first follicular wave. Reproduction 122 561-569.

Rice S, Ojha K \& Mason H 2008 Human ovarian biopsies as a viable source of pre-antral follicles. Human Reproduction 23 600-605.

Rodgers RJ, Waterman MR \& Simpson ER 1986 Cytochromes P-450scc, P-450(17) $\alpha$, adrenodoxin, and reduced nicotinamide adenine dinucleotide phosphate-cytochrome P-450 reductase in bovine follicles and corpora lutea. Changes in specific contents during the ovarian cycle. Endocrinology 118 1366-1374.

Rodgers RJ, van Wezel IL, Irving-Rodgers HF, Lavranos TC, Irvine CM \& Krupa M 1999 Roles of extracellular matrix in follicular development. Journal of Reproduction and Fertility 54 343-352.

Rodgers RJ, Irving-Rodgers HF, van Wezel IL, Krupa M \& Lavranos TC 2001 Dynamics of the membrana granulosa during expansion of the ovarian follicular antrum. Molecular and Cellular Endocrinology 171 41-48.

Rosenblatt J 2008 Mitosis: moesin and the importance of being round. Current Biology 18 R292-R293.
Ryan KE, Casey SM, Canty MJ, Crowe MA, Martin F \& Evans AC 2007 Akt and Erk signal transduction pathways are early markers of differentiation in dominant and subordinate ovarian follicles in cattle. Reproduction 133 617-626.

Schultz GS \& Wysocki A 2009 Interactions between extracellular matrix and growth factors in wound healing. Wound Repair and Regeneration 17 153-162.

Sirois J \& Fortune JE 1988 Ovarian follicular dynamics during the estrous cycle in heifers monitored by real-time ultrasonography. Biology of Reproduction 39 308-317.

Sisco B \& Pfeffer PL 2007 Expression of activin pathway genes in granulosa cells of dominant and subordinate bovine follicles. Theriogenology $\mathbf{6 8}$ 29-37.

Stubbs SA, Stark J, Dilworth SM, Franks S \& Hardy K 2007 Abnormal preantral folliculogenesis in polycystic ovaries is associated with increased granulosa cell division. Journal of Clinical Endocrinology and Metabolism 92 4418-4426.

Townson DH, Tsang PC, Butler WR, Frajblat M, Griel LC Jr, Johnson CJ, Milvae RA, Niksic GM \& Pate JL 2002 Relationship of fertility to ovarian follicular waves before breeding in dairy cows. Journal of Animal Science 80 1053-1058.

Wang Y, Asselin E \& Tsang BK 2002 Involvement of transforming growth factor $\alpha$ in the regulation of rat ovarian X-linked inhibitor of apoptosis protein expression and follicular growth by follicle-stimulating hormone. Biology of Reproduction 66 1672-1680.

Webb R, Campbell BK, Garverick HA, Gong JG, Gutierrez CG \& Armstrong DG 1999 Molecular mechanisms regulating follicular recruitment and selection. Journal of Reproduction and Fertility $\mathbf{5 4}$ 33-48.

Westergaard CG, Byskov AG \& Andersen CY 2007 Morphometric characteristics of the primordial to primary follicle transition in the human ovary in relation to age. Human Reproduction 22 2225-2231.

van Wezel IL \& Rodgers RJ 1996 Morphological characterization of bovine primordial follicles and their environment in vivo. Biology of Reproduction 55 1003-1011.

van Wezel IL, Dharmarajan AM, Lavranos TC \& Rodgers RJ 1999a Evidence for alternative pathways of granulosa cell death in healthy and slightly atretic bovine antral follicles. Endocrinology $\mathbf{1 4 0}$ 2602-2612.

van Wezel IL, Krupa M \& Rodgers RJ 1999b Development of the membrana granulosa of bovine antral follicles: structure, location of mitosis and pyknosis, and immunolocalization of involucrin and vimentin. Reproduction, Fertility, and Development 11 37-48.

Wolfenson D, Sonego H, Shaham-Albalancy A, Shpirer Y \& Meidan R 1999 Comparison of the steroidogenic capacity of bovine follicular and luteal cells, and corpora lutea originating from dominant follicles of the first or second follicular wave. Journal of Reproduction and Fertility 117 241-247.

Zheng X, Price CA, Tremblay Y, Lussier JG \& Carriere PD 2008 Role of transforming growth factor- $\beta 1$ in gene expression and activity of estradiol and progesterone-generating enzymes in FSH-stimulated bovine granulosa cells. Reproduction 136 447-457.

Received 29 April 2009

First decision 25 June 2009

Revised manuscript received 12 August 2009

Accepted 25 September 2009 